\section{Community College Pipeline Programs: Creating Successful Pathways to the Research University}

Catalina Ormsby

University of Michigan, acormsby@umich.edu

\section{doi: 10.18833/spur/2/1/2}

As public universities in Michigan play a key role in developing and retaining high-achieving students in the state, it is vital to ensure that community college students view the University of Michigan (UM) as an option for their future studies. The Michigan Community College Summer Research Fellowship Program (CCSFP), part of the Undergraduate Research Opportunity Program (UROP) at UM, provides a unique opportunity for community college students to engage in research. The program is tailored to recruit and retain a diverse student population, including historically underrepresented students, first-generation college students, student veterans, women in science, and students from lower income backgrounds. The primary purpose of CCSFP is to connect high-achieving community college students with research opportunities and mentors at UM and encourage them to apply and transfer to UM after their summer research experience on campus. This pipeline program provides potential transfer students from community colleges with an integrated transition program to help them make a successful academic, social, and personal transition to the university.

The program design and activities include:

- 10 weeks of full-time work with a UM research sponsor

- A fellowship stipend (maximum \$4,000)

- A two-day orientation, with a tour of the campus and resources

- Weekly enrichment research and professional seminars (on research methods, research ethics, networking, multicultural issues in research, growth mind-set, and student learning techniques)
- Four Journal Club meetings facilitated by graduate students

- Reflection Blog assignments and community service opportunities

- Brown Bag meetings with selected faculty and guest speakers

- Research skills and professional workshops (on SPSS, STATA, NVivo, and lab safety)

- Access to advising on application and admissions procedures, financial aid options, and transfer accreditation

- Opportunities to meet and network with a variety of campus leaders, faculty, alumni, students, and administrators

- Tours and field trips (to research labs, campus museums, and libraries)

- Participation in UROP's Annual Summer Symposium

Throughout the program, students make important connections on campus as they are exposed to the social, cultural, professional, and academic environment at the university and its wide variety of resources. Every summer, CCSFP fellows worked closely with a committed team of peer advisers, who meet with them throughout the summer regarding their research experience, faculty mentor relations, and transfer plans. The great success of the program is largely due to key cross-campus collaborations with the Office of Undergraduate Admissions and the Office of Financial Aid, among other departments. CCSFP also has partnerships with a wide range of community colleges in the state, including faculty, advisers, and student groups at these schools. The transfer rates of students participating in the program is approximately 80 percent, with graduation rates of 98 percent for the past four years. The university is investing in increasing the number of transfer students coming from community colleges. The impact and benefits of CCSFP serve as a recruiting tool and a retention and integration approach for a diverse group of talented students. The program hopes to expand its transfer initiatives to a broader population of community college students and promote collaboration with community colleges at a national level. 